This is a post-peer-review, pre-copyedit version of an article published in Cognitive, Affective \& Behavioral Neuroscience. The final authenticated version is available online.

\title{
The Semiotics of the Message and the Messenger: How Non-Verbal Communication Affects Fairness Perception
}

\author{
Michiel Spape ${ }^{1,2,3}$, Ville Harjunen ${ }^{3}$, Imtiaj Ahmed ${ }^{2}$, Giulio Jacucci ${ }^{2}$ \& Niklas Ravaja ${ }^{3}$
}

1. Department of Psychology, Liverpool Hope University, United Kingdom

2. Department of Computer Science, University of Helsinki, Finland

3. Department of Psychology and Logopedics, University of Helsinki, Finland

Nonverbal communication determines much of how we perceive explicit, verbal messages. Facial expressions and social touch, for example, influence affinity and conformity. To understand the interaction between non-verbal and verbal information, we studied how the psychophysiological time-course of semiotics - the decoding of the meaning of a message - is altered by interpersonal touch and facial expressions. A virtual reality-based economic decision-making game of Ultimatum was used to investigate how participants perceived, and responded to, financial offers of variable levels of fairness. In line with previous studies, unfair offers evoked medial frontal negativity (MFN) within the N2 time window, which has been interpreted as reflecting an emotional reaction to violated social norms. Contrary to this emotional interpretation of the MFN, however, nonverbal signals did not modulate the MFN component, only affecting fairness perception during the $P 3$ component. This suggests that the non-verbal context affects the late, but not the early stage, of fairness perception. We discuss the implications of the semiotics of the message and the messenger as a process by which parallel information sources of "who says what" are integrated in reverse order: of the message, then the messenger.

Keywords: EEG, ERP, MFN, economic decision-making, non-verbal communication, emotional expressions, touch, neurosemiotics.

\section{Introduction}

A common myth is that "in every social encounter, nearly two-thirds of the interaction meaning is derived through nonverbal messages" (e.g. TingToomey, 1999). This is an extreme overinterpretation of a classic series of studies by Albert Mehrabian (1971). Mehrabian \& Ferris (1967) for instance showed that an attitude towards a stranger saying "maybe" was approximately 1.5 times more affected by seeing the stranger's facial expression than by their tone of voice. Another key study showed that participants placed more emphasis on the tone of voice than on verbal content whilst rating the attitude of one stranger speaking to another (Mehrabian \& Wiener, 1967). These findings led to the famous equation that communicating attitude (feeling or liking) equals $55 \%$ body language $+38 \%$ tone of voice $+7 \%$ language (Mehrabian, 1971, p.434). However, such definite numbers of course belie the extreme breadth and complexity of communication: how we evaluate a message can well be defined by its contents (e.g. a demand for tax vs a profession of love) more than by the body language it is accompanied by. And yet, it is clear that non-verbal context does influence appraisal: Emotional responses to television messages are affected by presentation attributes, such as colour, motion, and screen size (Detenber, Simons, \& Reiss, 2000; Ravaja, 2004; Reeves, Lang, Kim, \& Tatar, 1999).

Determining what a message signifies, the semiotics, thus depends on a variety of modalities and contextual factors, and must rely on a network of different neural structures that drive an interplay of cognitive functions. For example, language can dramatically affect emotion perception (Barrett, Lindquist, \& Gendron, 2007), and emotional context determines which brain areas are activated while understanding short sentences as either literal or ironic (Eviatar \& Just, 2006). A similar finding that is of particular present relevance is that receiving a message of an unfair proposal in an economic decision-making game elicits activity in areas related to emotion as well as cognition (Sanfey, Rilling, Aronson, Nystrom, \& Cohen, 2003). Likewise, the facial appearance of the bringers of offers, and the mood of those who received them, was found to determine how such messages were processed (Ma, Qian, Hu, \& Wang, 2017; Riepl, Mussel, Osinsky, \& Hewig, 2016).

Yet, while it is widely accepted that emotional processes and non-verbal behaviour contribute to behaviour, surprisingly little is known about the cognitive neurodynamics that determine the interplay between a message and its nonverbal context, as provided by its messenger. If non-verbal context affects how a message is evaluated, then neural processes associated with the evaluation should be critically determined by behaviour of the messenger. To some extent, this has been studied 
using priming paradigms in which both prime (the context, e.g., a smiling messenger) and probe (e.g., a positive stimulus) have affective content. Eventrelated potentials studies show, however, that the emotional context sometimes does (Ravaja, Harjunen, Ahmed, Jacucci, \& Spapé, 2017), and sometimes does not, modulate the emotional processing of the message (Schupp, Schmälzle, Flaisch, Weike, \& Hamm, 2013). Of course, in real, social situations as opposed to priming paradigm, the nonverbal context and message are both related to a single source, the messenger. Because the messenger displays a certain emotional state (e.g. anger), we may expect a negative message, resulting in a top-down, biased perception of the actual communication. Conversely, it is equally possible that the context is only processed after the message itself is evaluated, for example due to the operation of feature integration mechanism (Kahneman, Treisman, \& Gibbs, 1992; Treisman, 1996).

1.1 The message: The neurodynamics of message evaluation in the Ultimatum Game

To investigate the neurodynamics of how a messenger's nonverbal behaviour affects the semiotics of a message, we used the classic behavioural economics game of Ultimatum (Güth, Schmittberger, \& Schwarze, 1982). In the Ultimatum Game, as also used by the aforementioned Sanfey et al. (2003), participants respond to offers from a hidden proposer, who decides how a given amount of money is divided between the two. If the participant agrees, each gets their pay-out, while declining an offer results in an outcome of nothing for either party. While economically costly, rejection of unfair offers is a common finding in the Ultimatum Game, which implies a critical role of irrational motives (von Neumann \& Morgenstern, 1944). Due to this, the Ultimatum Game provides a powerful standard to operationalize social, cognitive and affective contributions to message evaluation by studying their influences on offer rejection. Studies of event-related potentials add to this by revealing the temporal dynamics of emotional evaluation of offers (Boksem \& De Cremer, 2010).

Boksem \& De Cremer (2010), following Polezzi et al. (2008) used this economic decision-

\footnotetext{
${ }^{1}$ We mention them as MFN/FRN here, as in our view, both are similarly manifestations of the class of MFNs that arise from the perception that an outcome fails expectation (Gehring \& Willoughby, 2004). Classically, FRN requires this expectation to be about one's own performance (commonly a binary, positive or negative cue), while the MFN may be an interpersonal message. Thus, Boksem \& De Cremer (2010) speak of MFN: Offers in
}

making game and showed that perceiving an unfair offer results in medial frontal negativity (MFN), which they related to a matching process between a social norm of fairness, and the present reality of unfairness. The MFN is, beyond the literature on the Ultimatum Game, related to a broad class of ERP components that describe a type of error, such as with incorrect responses indexed by the error related negativity (ERN, Gehring, Goss, Coles, Meyer, \& Donchin, 1993), incongruence between primed and task-relevant actions resulting in the $\mathrm{N} 2 \mathrm{~b}$ (Nieuwenhuis, Yeung, van den Wildenberg, \& Ridderinkhof, 2003), and feedback indicating a loss or failure indexed by the feedback-related negativity (FRN, Gehring \& Willoughby, 2002) ${ }^{1}$. These components are similar in functional, topographical and temporal characteristics in the sense that all involve performance monitoring functions, a similar fronto-centrally negative topography, and a common latency of at least 200 ms post stimulus (Folstein \& Van Petten, 2008). This has led to the suggestion that the same, anterior cingulate located neural generator is activated whenever performance seems 'worse than expected', irrespective of paradigm, giving rise to both the ERN, and the FRN/MFN (Holroyd \& Coles, 2002; but see Gehring \& Willoughby, 2004).

Aside from the MFN, the message context may affect emotional evaluation during other stages of stimulus processing as well. Preceding the MFN by about $100 \mathrm{~ms}$, the $\mathrm{N} 1$ is the first clear negative visual evoked potential and is characterised by a predominantly frontal topography and an onset at ca. 100 ms (Harter \& Previc, 1978; Spitz, Emerson, \& Pedley, 1986). Previous studies have shown it is enhanced in response to emotionally relevant stimuli, which may be due to an early attentional mechanism that prioritises evolutionary salient pleasant and unpleasant arousing stimuli (Schupp, Junghöfer, Weike, \& Hamm, 2003), such as dangerous animals and fearful facial expressions (Zhang, Luo, \& Luo, 2013). While there are few studies explicitly measuring the effect of non-verbal contexts on the N1, Schirmer et al. (2010) found a particular effect of interpersonal touch on this early component, showing that a simple touch enhances the N1 to emotion-evoking pictures, potentially

their version of the Ultimatum Game do not concern a previous action from the participant, as each trial is seen as a single-shot decision game. Spapé, Hoggan, Jacucci, \& Ravaja (2015), however, investigated how participants were affected by a computer's decision to reject/accept their offer; accordingly focussing on the FRN, not the MFN. Although the subtle distinction is critical, it is not used consistently in the literature. 
arguing in favour of a top-down effect of context on salience-related processing.

Peaking after the MFN, the P3 is a complex, late potential that is characterised by three components: the $P 3 a$, the $P 3 b$, and the Late Positive Potential (LPP). The $\mathrm{P} 3 \mathrm{a}$ commonly has a more frontal topography, a somewhat earlier latency (at ca. 300 $\mathrm{ms})$, and is sometimes referred to as the "novelty"related P3 (Friedman, Cycowicz, \& Gaeta, 2001). The P3b (or "classic P300"), in contrast, has a more parietal topography, and is commonly identified, but enhanced if a stimulus is unexpected, meaningful or task-relevant (Squires, Squires, \& Hillyard, 1975; Sutton, Braren, Zubin, \& John, 1965; Sutton, Tueting, Zubin, \& John, 1967). More variegated emotional differentiation can often be observed in this interval, for instance, with fearful and happy facial emotional expressions distinctly affecting the P3 potential in emotion classification tasks (Luo, Feng, He, Wang, \& Luo, 2010; Spapé, Harjunen, \& Ravaja, 2017).

Finally, the LPP is not always clearly distinguishable from the $\mathrm{P} 3 \mathrm{a}$ or $\mathrm{P} 3 \mathrm{~b}$, and has been identified at frontal as well as parietal sites, and a latency following the initial P300 (Krolak-Salmon, Fischer, Vighetto, \& Mauguière, 2001; Schupp et al., 2004). The LPP has been found to be sensitive to faces requiring more elaborate processing, and its measurement allows discrimination between different emotional expressions such as happiness, anger, fear, surprise and disgust (Krolak-Salmon et al., 2001; Schupp et al., 2004; Spapé et al., 2017). Such more nuanced emotional appraisal might define a stimulus in an approach-avoidance type of dimension, which has been related to the LPP (Bamford et al., 2015; Gable \& Harmon-Jones, 2010). Likewise, in the context of the Ultimatum Game, it was found that the LPP was sensitive to a more socially qualified sense of unfairness: unfairness amplified the LPP only if others were (supposedly) treated even worse than the participant themselves (Wu, Zhou, van Dijk, Leliveld, \& Zhou, 2011).

\subsection{The messenger: Two channels of non-verbal communication}

To study how non-verbal behaviour affects semiotics, we investigate whether and when two common non-verbal channels, emotional expressions and interpersonal touch, modulate the difference between processing of fair and unfair offers in the Ultimatum Game, also referred to as fairness perception (Moser, Gaertig, \& Ruz, 2014). Accumulating evidence suggests that seeing another person smiling or frowning potentiates a perceiver's attention and early sensory-perceptual processes (Hinojosa, Mercado, \& Carretié, 2015; Luo et al., 2010). As a result, emotional expressions can have strong effects on cognition and, ultimately, decisionmaking. Proposals accompanied by smiles are more likely to result in signed petitions (Vrugt, 2007), help in picking up dropped items (Gueguen \& De Gail, 2003), and accepted offers in the Ultimatum Game (Mussel, Göritz, \& Hewig, 2013).

Another common non-verbal channel of communication that has received much interest in affective neuroscience and decision making is touch. Touch may be a particularly influential social cue due to its necessarily intimate nature and sensitivity to other contextual factors (Gazzola et al., 2012; Ravaja, Harjunen, Ahmed, Jacucci, \& Spapé, 2017). For instance, even a causal touch from a stranger has been found to increase appreciation, prosociality and compliance in the receiver (Fisher, Rytting, \& Heslin, 1976; Goldman \& Fordyce, 1983; Guéguen \& Fischer-Lokou, 2003). Crusco and Wetzel (1984), who first demonstrated this Midas touch-effect, found that waiters touching their customers during the service got larger tips than those who did not touch. The effect has since been replicated in various field and laboratory studies (Gallace \& Spence, 2010). It is thus clear that both facial expressions and touch do affect receivers' decisions, even if the underlying neural mechanisms and the temporal dynamics of the semiotic modulation remain obscure.

\section{The message and the messenger: Present study}

In order to investigate how the non-verbal behaviour of a messenger affects the evaluation of their message, it is essential to present both aspects as part of the same embodied source. As we argued elsewhere (Ravaja et al., 2017), this is not usually feasible in a classic laboratory setup: Presenting a touch followed by an offer is not the same experience as showing a person 'touching you' and the same person then making an offer. To enable the latter scenario, we used virtual reality presenting both the emotional expression and touch originating from the same artificial agent.

The principal aim of the study was to find out whether and when the non-verbal channels would modulate offer evaluation. If non-verbal channels do not affect offer perception at all, they should not interact with the message content (the type of offer), in terms of their effect on ERP components. In this case, the non-verbal context could still be observable as main effects of message context, for example touch might amplify salience detection, resulting in a generally increased N1 (Schirmer et al., 2010). Of more interest, however, would be evidence of biased offer perception observed as interactions between non-verbal context and message content. These should not be observed on N1, as message content is theoretically not yet decoded at this stage. However, 
an immediate interaction between fairness and context found on the MFN could indicate a top-down influence. For example, if a smile or touch promotes a prediction of a positive message, then unfair offers should be perceived as 'worse than expected' (Holroyd \& Coles, 2002), consequently incurring a stronger MFN to unfair relative to fair offers. On the other hand, if the non-verbal context affects later, bottom-up appraisal processes, the interpretation of the unfair offer could conflict with its smiling context, resulting in enhanced requirements for context updating (Donchin \& Coles, 1988) and therefore affecting the P3 or LPP components.

\section{Methods}

\subsection{Participants}

Thirty-one male and thirty-five female participants were recruited for the experiment. They were all students from the University of Helsinki and Aalto University with mean age of 24.37 ( $S D=3.45$, range = 19-46) years and with no history of neurological or psychiatric disorders. The participants were briefed about the purpose of the experiment to the extent that the study concerned social decision-making in virtual reality. The participants were also told that the agents' behaviour was guided by an algorithm approximating human behaviour in similar situation. Before asking to sign the informed consent and commencing the experiment, participants were informed about their right to withdraw from the study at any time without fear of negative consequences. The study was conducted in accordance with the guidelines set out in the Declaration of Helsinki and was approved by the Aalto Ethic Committee. The amount of money they earned as part of the Ultimatum Game ( $M=39.91$, $S D=3.45$ euros) was paid to the participant as a compensation for their participation, or in case the cumulative earnings were below a minimum compensation of 35 , the amount of 35 euros was paid.

\subsection{Stimuli and Apparatus}

Tactile stimuli were presented using a haptic glove, which used a motor to tighten elastic fabric over the hand. Technical details of the custom glove are provided by Ahmed et al. (2016), who found that this type of tactile feedback was judged as more natural and better suited to computer-mediated tactile communication than traditional vibrotactile actuators.

Visual stimuli were presented via a headmounted display (HMD, Oculus Rift DK2), which used positional tracking, stereoscopic displays (1920 x 1200 pixels per eye; $75 \mathrm{~Hz}$ refresh rate; $100^{\circ}$ nominal field of view) and parallax cues to provide an immersive visual experience. A similar tactileaugmented setup was used by Ravaja et al. (2017), who likewise portrayed virtual agents to present emotional expressions. However, instead of the one agent used by Ravaja et al. (2017), we used 8 different agents to improve the impression that each Ultimatum Game scenario was distinct from the previous one (similar to De Melo, Gratch, Carnevale, \& Read, 2012). The 3D models of the agents were manually morphed from Genesis 2 male and female characters of Daz Studio (Daz Productions Inc., Salt Lake City, UT), and modelled after real life male and female people from four ethnic backgrounds (European, African, South-East Asian, and Central Asian). Dynamic emotional expressions were designed using Unity 3D 4.5.4 software (Unity Technologies, San Francisco, CA), manipulating the facial action-units involved in prototypical expressions of happiness and anger (Ekman \& Friesen, 1971).

An Intel based desktop PC was used to run custom software, designed using Unity 3D software, to control stimulus presentation, recording of reactions and communication with the EEG amplifier. A photo-sensor and an accelerometer were used to additionally record the onset of visual and tactile stimuli, in order to improve the synchronization and validate timing accuracy. Timing, topography and signal-to-noise ratio of the virtual reality setup were recently tested and validated in a traditional oddball experiment (Harjunen, Ahmed, Jacucci, Ravaja, \& Spapé, 2017).

\subsection{Procedure}

After receiving instructions, signing of informed consent, and setting up of the EEG equipment, participants received assistance in putting on the HMD and fitting on the tactile glove. The experiment comprised one training block of 18 trials, and 8 experimental blocks of 72 trials. Upon completing a block, participants were asked to take a short selftimed break, during which they also received feedback on how much money they had accumulated thus far. During training, participants received additional instructions on the need to avoid movements and on the need to respond soon after but not during presentation of the offers. They received full debriefing after the final block, which was $83.5(S D=10.6)$ minutes after the start of the experiment on average.

Figure 1 summarizes the presentation and timing of events during experimental trials. Trials started with the word "Respond", cuing the role of the participant as a responder or "Propose" as a proposer. The latter were included in view that previous studies (Boksem \& De Cremer, 2010; Spapé, 
Hoggan, Jacucci, \& Ravaja, 2015) used similar schemes to enhance the realism of responder trials; they were, however, not further considered for analysis. Following a duration of $4000 \mathrm{~ms}$, for the trials with a new role, or $800 \mathrm{~ms}$ for every subsequent one, the interaction scenario was presented: a table showing a green area to the right, and the participant's virtual hand. Moving the hand over the green area was used as a trigger to show the virtual agent, as a well as a blue manual fixation cross-hair. Moving their hand over this position started 0-200 ms of random delay, followed by a 1000 ms animation in which the emotional expression (anger, neutral, happiness) and physical interaction (none, visual touch, tactile touch) was dynamically displayed. In the visual and tactile touch conditions, the virtual hand moved towards the participant's, reaching it at $1000 \mathrm{~ms}$. In the tactile touch condition, this additionally started $500 \mathrm{~ms}$ of tactile feedback using the glove. In all three conditions, the animation was otherwise static for 500-700 ms. The interaction scenario was then replaced by a fixation cross-hair with a duration of 100-300 ms (randomized), before the proposal from the agent was shown. The proposal was shown as two numbers, the upper one representing the amount for the agent and the lower the amount for the subject, with a frame around the two numbers to indicate that the upper number referred to the person on the other end of the table. The proposal was always shown for $900 \mathrm{~ms}$, followed by a response cue. Pressing the left button on the keypad (below the participant's left hand) would accept the response while the right button would reject it. The next trial was presented after a blank inter-trial interval of $500 \mathrm{~ms}$.

\subsection{Design}

The experiment consisted of 8 blocks of 72 trials. In each block, the three types of touch (no touch, visual touch, tactile touch), three types of emotional expression (angry, neutral, happy) and four types of offers: (very unfair: $2|18,3| 17,4|16,5| 15,6 \mid 14$, unfair: $7|13,8| 12$, fair: $10 \mid 10$, generous: $11|9,12| 8$, $13|7,14| 6,15 \mid 5)$ were randomly mixed and repeated twice. The pool of offer sizes was based on Boksem and De Cremer (2010), who used a skewed distribution such that the probability of more equal offers was higher than less equal ones. In the present study, $6.7 \%$ were $2 \mid 18$ offers, $13.3 \%$ were $3 \mid 17$, $20.0 \%$ were $4 \mid 16,26.7 \%$ were $5 \mid 15$ and $33.3 \%$ were $6 \mid 14$; of unfair ones, $46.2 \%$ were $7 \mid 13$ and $53.8 \%$ were $8 \mid 12$. Boksem and De Cremer (2010) did not use generous offers, so each specific offer was provided $20 \%$ of times. In each block, the first, second, third, or fourth 18 trials were randomly selected to appear as proposer trials. Each block was further subdivided into 4 series of 18 trials each, with one (random) series comprising proposer trials and the others responder trials. Statistical analyses were run over the 432 responder trials, with ERPs calculated over a maximum of 36 trials, for two repeated measures ANOVAs: one with offer size (4 levels) and emotional expression (3 levels), and one with offer size, and touch (3 levels).

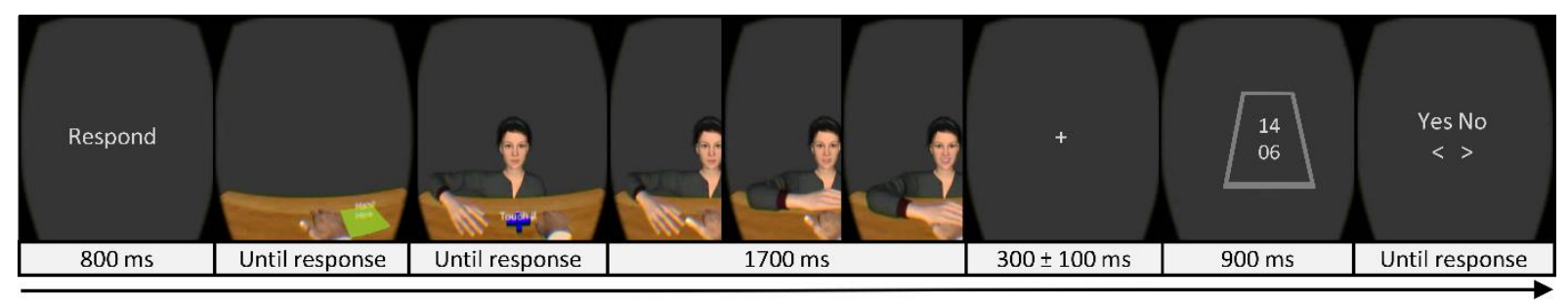

Figure 1: schematic presentation of a trial sequence. 


\subsection{EEG Recording and Pre-Processing}

A QuickAmp (BrainProducts $\mathrm{GmbH}$, Gilching, Germany) amplifier was used to record EEG at 1000 $\mathrm{Hz}$ with a hardware band-pass filter from 0.01 to 500 $\mathrm{Hz}$ from equidistantly placed $\mathrm{Ag} / \mathrm{AgCl}$ scalp electrodes, positioned using EasyCap elastic hats (EasyCap GmbH, Herrschin, Germany). EEG was recorded from sites overlying Fp1, Fp2, F7, F3, Fz, F4, F8, FT9, FC5, FC1, FC2, FC6, T7, C3, Cz, C4, T8, TP9, CP5, CP1, CP2, CP6, TP10, P7, P3, Pz, P4, P8, O1, Oz and 02 of the $10-10$ system (Chatrian, Lettich, \& Nelson, 1985). Horizontal and vertical electrooculographic (EOG) activity was recorded using two pairs of electrodes, respectively placed $1 \mathrm{~cm}$ laterally to both eyes, and superior and inferior to the right eye.

EEG pre-processing included a band-pass filter between 0.2 and $80 \mathrm{~Hz}$ with a notch filter at $50 \mathrm{~Hz}$. Artifact correction used independent component analysis (ICA) using the logistic infomax algorithm as implemented in EEGLAB (Delorme \& Makeig, 2004), with extended parameters (learning rate $=.001$, learning rate lowered by $2 \%$ if angle $\Delta<60^{\circ}$, learning ending after 512 steps or weight change $<1 E 07$. For full code, see EEGLAB runica algorithm version 25 January 2002, https://github.com/sccn/eeglab). The ICA was run on epochs of $7 \mathrm{~s}$, time-locked to the offer onset, with $3.5 \mathrm{~s}$ of baseline activity. Following this, we visually inspected the components for the presence of abnormal frequency spectra, topographies suggesting ocular dipoles, and the absence of event-related activity. The source-level EEG was then reconstructed by applying the artefactfree weights to the unfiltered, continuous data.

Following the artefact correction, we followed common steps in the MFN / Ultimatum Game literature (e.g. Boksem \& De Cremer, 2010; Van der Veen \& Sahibdin, 2011; Wu, Zhou, van Dijk, Leliveld, \& Zhou, 2011): applying a linked mastoid reference and a $40 \mathrm{~Hz}$ low-pass filter before segmenting the data into $1 \mathrm{~s}$ epochs, time-locked to the onset of the offer and including $200 \mathrm{~ms}$ of baseline activity. To further remove the effects of artefacts, we applied an individually tailored threshold-based artifact rejection procedure which used a stair-climbing procedure, which removed on average $4.6(S D=4.8)$ $\%$ of epochs by applying a maximum threshold between 27-68 $\mu \mathrm{V}$ and a maximum max-min difference between 27-90 $\mu \mathrm{V}$. Following removal procedures based on behavior (see below) and of participants who had in any design cell fewer than 25 epochs, we used an average number of 34.5 (SD = 1.2) epochs per design cell to calculate individual ERPs.

\subsection{ERP time window definition and analysis}

Consistent with the literature on the FRN/MFN (Holroyd \& Coles, 2002; Van der Veen \& Sahibdin, 2011; Yeung, Botvinick, \& Cohen, 2004), we focussed the analysis on midline frontal electrodes $\mathrm{Fz}$ and $\mathrm{Cz}$, and included the $\mathrm{Pz}$ for additional investigation of the P3. The N1 was defined as the first clearly visible, negative peak with a frontal topography, defined over the average across conditions as the first local minimum. This was observed at $105 \mathrm{~ms}(-4.76 \mu \mathrm{V})$, corresponding to previous studies (Holmes, Vuilleumier, \& Eimer, 2003), and we defined a $50 \mathrm{~ms}$ window centred on this latency $(80-130 \mathrm{~ms})$ as the measurement of N1. We used a data-driven approach, partially inspired by Boksem \& De Cremer (2010) to define the MFN. As the analysis concerned the modulation (rather than the main effect) of the MFN and later potentials, we used a windowed repeated measures ANOVA with fairness (very unfair, unfair, fair and generous) as factor and mean voltage of $10 \mathrm{~ms}$ bins as dependent. This showed an early effect from $230 \mathrm{~ms}$ to $350 \mathrm{~ms}$ over $\mathrm{Fz}$ (peaking at $250 \mathrm{~ms}, \mathrm{~F}(2,56)=11.84, \mathrm{p}<.001)$. As will be seen from Figure 3 , the fair condition contributed much stronger to the differences than any other condition. Thus, after removing the fair condition from the analysis, the earliest effects of fair offers shifted to $400-600$ in $\mathrm{Fz}$, while later effects were observed in $\mathrm{Cz}$ and $\mathrm{Pz}$ (both from 530 to 780). Accordingly, we used three windows that defined the classic MFN (230 to 350 ) - in which there was any effect of fairness - and later windows that had effects of offer size. As the earlier part of this effect of offer size showed a more frontal - and the latter a more parietal topography, we defined these as respectively P3 $(400-580)$ and LPP $(580-780)$. The analyses for each window were based on 36 amplitude averages, as with 3 emotional expressions (happy, neutral, angry) or 3 types of touch (no touch, visual touch, tactile touch), 4 offer sizes (very unfair, unfair, fair and generous) and 3 electrodes ( $F z, C z$, $\mathrm{Pz})$.

\subsection{Statistical analysis}

Three sets of analyses were conducted. We first investigated the behavioural effects (3.1) within a single repeated measures ANOVA with emotional expression, touch, and offer size as factors and acceptance as dependent variable. The focus of the present study constituted the analysis of the ERPs. For this, we ran two repeated measures ANOVAs: one to investigate the effect of emotional expression on offer perception (3.2), and the second to investigate the effect of touch on offer perception (3.3). This approach allowed us to ascertain sufficient number of epochs per design cell for ERP analysis; and to reduce the likelihood of type-I error 
reporting ${ }^{2}$. As we made no specific hypothesis that the emotional expression would influence the effect that touch has on offer evaluation, and as such hypothesis was not supported by the behavioural evidence reported further, we decided to reduce the complexity towards two 4-way repeated measures ANOVAs, testing against an adjusted significance level of $p<.0125$, see 3.2). First, an ANOVA was conducted with emotional expression (anger, neutral, happiness), fairness (very unfair, unfair, fair, generous), electrode ( $\mathrm{Fz}, \mathrm{Cz}, \mathrm{Pz})$, and time (N1, MFN, P3, LPP) as factors. To analyse the time-course of effects, each time-window was further investigated with 3-way interactions. A second, similar ANOVA was run, but with touch (none, visual, visuo-tactile), offer size, electrode, and time, as factors. Regarding fairness, it will become clear over the course of the analysis that fair offers show a pronounced contrast with all other offer types. To dissociate the singular effect of fairness from the more variegated difference between various offers, we follow up any significant effect of fairness with the same analysis but exclude the fair level. We refer to this follow-up analysis as investigating the factor of offer size (very unfair, unfair, generous). Main effects of electrode are not reported, as are redundant effects in common between conditions (e.g. effects of offer size). Greenhouse-Geisser correction is applied when necessary. Non-significant, theoretically interesting findings are reported along with observed power estimates.

\section{Results}

An initial analysis of the behavioural and EEG data was used to determine whether participants should be excluded from the dataset. Three participants accepted more than $95 \%$ of offers in the two unfair conditions. Another three participants were removed for accepting substantially (10\%) fewer generous than fair offers. Finally, three participants were excluded for having fewer than 25 epochs per design cell left following artefact rejection. The final sample consisted of 57 participants (33 females, 24 males), age $M=24.37, S D=4.98$ years.

\footnotetext{
${ }^{2}$ Of course, while running the ERP analysis over the ful factorial five-way analysis is not optimal for the aforementioned reasons, it is certainly possible. The
}

\subsection{Effects of emotional expression and touch on behaviour}

A repeated measures ANOVA with fairness (very unfair, unfair, fair, and general), touch (none, visual touch, tactile touch), and emotional expression on acceptance (\%) showed significant effects of fairness, $\mathrm{F}(2.05,114.88)=205.06, \mathrm{MSE}=3920.53, \mathrm{p}<.001$, $\eta_{p}^{2}=.79$, and emotional expression, $\mathrm{F}(1.12,62.76)=$ 15.14, MSE $=1778.57, \mathrm{p}<.001, \eta_{p}^{2}=.21$, but not touch, $\mathrm{F}(1.81,101.24)=1.29$, MSE $=75.59, \mathrm{p}=.28$, $\eta_{p}^{2}=.02$, power $=.26$. Planned comparisons with incremental levels of fairness showed that unfair offers were accepted more often $(74.20 \%)$ than very unfair ones $(26.65 \%), t(56)=13.34, p<.001$, and fair offers $(95.04 \%)$ more often than unfair offers. Generous offers (97.06\%) were not significantly more often accepted than fair offers, $p=.07$. Contrasts of the emotional expressions vs the neutral condition showed the main effect of emotional expression to primarily indicate that fewer offers were accepted after angry (67.82\%) than neutral (75.72\%) emotional expressions, $t$ (56) = $4.06, p<.001$. Happy emotional expressions did not significantly result in more offers being accepted, $p=$ .45 .

A significant interaction of emotional expression and fairness was observed, $\mathrm{F}(3.24,181.20)=2.98$, $\mathrm{MSE}=341.39, \mathrm{p}=.029, \eta_{p}^{2}=.05$. As shown in the left panel of figure 2, the effect indicated an increased difference between angry and happy as well as angry and neutral expression conditions in fair (happy angry $=9.06 \%$; neutral - angry $=8.54 \%$ ) and unfair condition (happy - angry $=12.73 \%$; neutral - angry = $11.66 \%$ ), as compared to very unfair (happy - angry $=5.98 \%$; neutral - angry $=5.96 \%$ ) and generous condition (happy - angry $=5.63 \%$; neutral - angry = $5.43 \%)$. The predicted interaction between fairness and touch was not observed, $\mathrm{p}=.40, \eta_{p}^{2}=.02$, power $=.41$, nor did touch interact with emotional expression, $\mathrm{p}=.68, \eta_{p}^{2}=.01$, power $=.19$, or enter a three-way interaction with both emotional expression and fairness, $\mathrm{p}=.82, \eta_{p}^{2}=.01$, power $=$ .37.

interested reader can verify the outcome of such an analysis in Supplementary Material 1. 

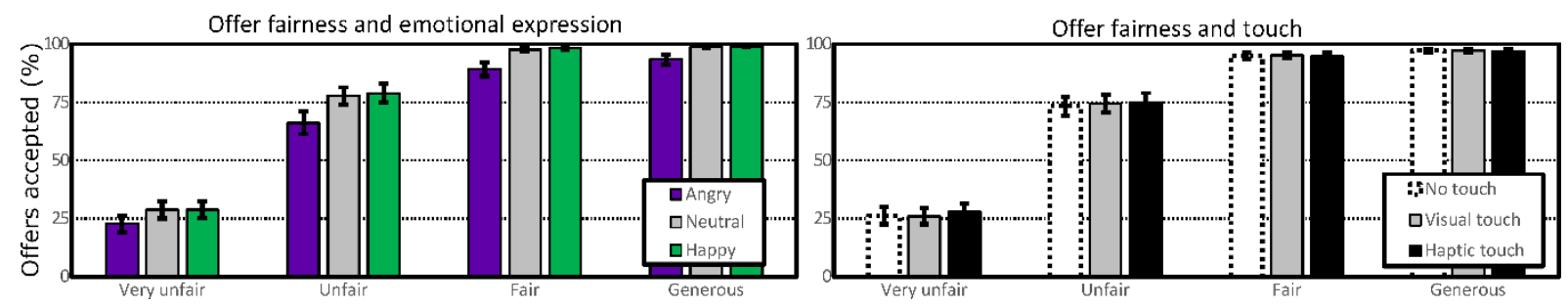

Figure 2: Behavioural effects. Left: Offer acceptance as a function of fairness of offer and emotional expression. Right: Offer acceptance as a function of fairness and interpersonal touch. Error bars show standard error of means.

\subsection{Effects of emotional expression and fairness on the ERP}

A repeated measures ANOVA on the average amplitude with time (N1, MFN, P3, LPP), electrode $(\mathrm{Fz}, \mathrm{Cz}, \mathrm{Pz})$, emotional expression (angry, neutral, happy), and fairness (very unfair, unfair, fair, generous) showed a significant effect of time, $F$ $(2.42,1.31)=103.49, \mathrm{MSE}=223.11, \mathrm{p}<.001, \eta_{p}^{2}=$ .65 , emotional expression, $\mathrm{F}(1.88,105.18)=14.95$, MSE $=1080.85, \mathrm{p}<.001, \eta_{p}^{2}=.21$, but not offer size, $\mathrm{p}=.06$. Time interacted with fairness, $\mathrm{F}$ (5.16, $288.89)=34.37, \mathrm{MSE}=14.44, \mathrm{p}<.001, \eta_{p}^{2}=.38$, and emotional expression, $\mathrm{F}(4.69,262.53)=6.28$, MSE $=$ $4.24, \mathrm{p}<.001, \eta_{p}^{2}=.10$. The interaction between emotional expression and fairness was not significant, $p=.054$, but the three-way interaction between time, emotional expression, and fairness was, $\mathrm{F}(10.97,614.41)=2.54, \mathrm{MSE}=4.30, \mathrm{p}=.004$, $\eta_{p}^{2}=.04$. Therefore, the effects of emotional expression, fairness and the interaction between the two factors, played out over different potentials, for which reason we split the above analysis into ANOVAs and separately examined the N1, MFN, P300 and LPP with alpha level at $p<.0125(5 \% / 4)$ to adjust for type-I errors.

\subsubsection{Effects of emotional expression and fairness on $\mathrm{N} 1$}

Repeated measures ANOVA on average amplitude over the $\mathrm{N} 1$ interval with electrode ( $\mathrm{Fz}, \mathrm{Cz}, \mathrm{Pz})$, fairness (very unfair, unfair, fair, generous) and emotional expression (angry, neutral, happy), showed that neither fairness, $\mathrm{p}=.024, \eta_{p}^{2}=.06$, power $=.51$, nor emotional expression, $p=.016,, \eta_{p}^{2}$ $=.07$, power $=.53$, was significant (given $\alpha=.0125$, see 3.2$)$.

\subsubsection{Effects of emotional expression and fairness on MFN}

Repeated measures ANOVA on average amplitude over the MFN interval with electrode ( $\mathrm{Fz}, \mathrm{Cz}, \mathrm{Pz})$, fairness (very unfair, unfair, fair, generous) and emotional expression (angry, neutral, happy), showed that fairness was significant, $\mathrm{F}(2.55,142.79)$ $=16.93, \mathrm{MSE}=11.25, \mathrm{p}<.001, \eta_{p}^{2}=.23$, as was emotional expression, $\mathrm{F}(1.81,101.26)=8.63$, MSE $=$ 11.55, $\mathrm{p}=.001, \eta_{p}^{2}=.13$. Emotional expression furthermore interacted with electrode, F (2.55, $142.58)=5.17, \mathrm{MSE}=1.21, \mathrm{p}=.003, \eta_{p}^{2}=.08$. Emotional expression was found to mainly signify a difference between the two emotional conditions (angry $=3.63 \mu \mathrm{V}$, happy $=3.76 \mu \mathrm{V}$ ) and neutral (3.08 $\mu \mathrm{V})$. The interaction with electrode showed the effect to apply more to the central $(0.81 \mu \mathrm{V})$ and frontal $(0.68 \mu \mathrm{V})$ electrodes than the parietal one $(0.37 \mu \mathrm{V})$.

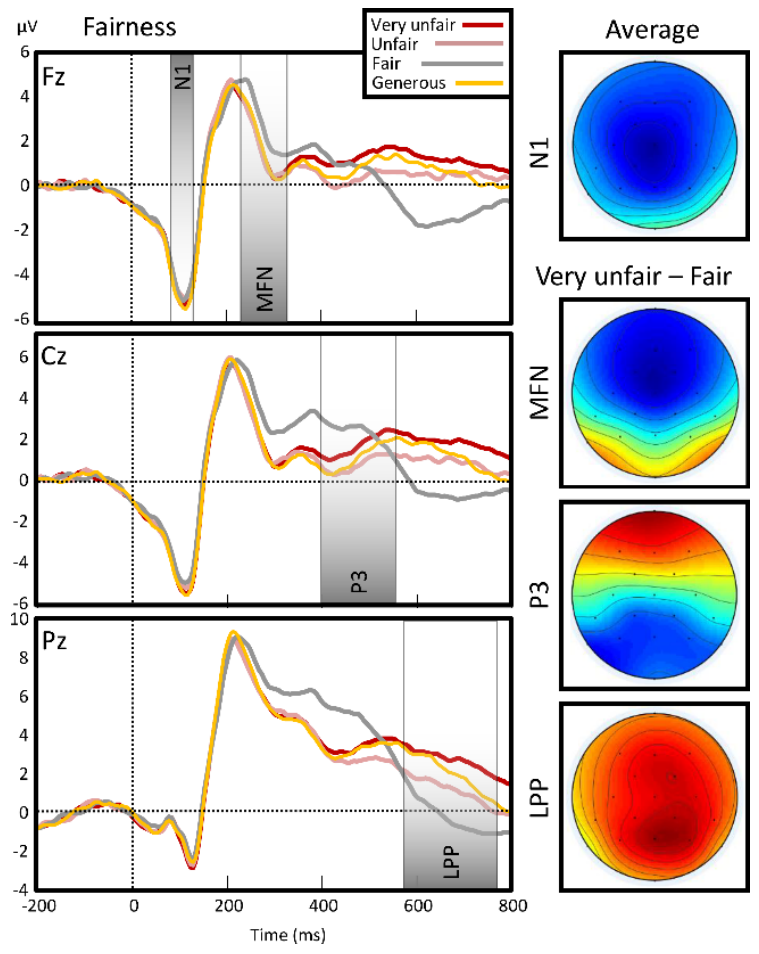

Figure 3: Event related potential to the offer as a function of fairness. Topographies show distribution of voltage for the general $\mathrm{N} 1$ potential (averaged across conditions) and for the fairness effect in the medial frontal negativity (MFN), P3 and late positive potential (LPP) intervals. The fairness effect was calculated as the difference between very unfair (red) and fair (grey) offers.

Of more interest was the effect of fairness: this showed mainly an effect of fair offers evoking more positivity than unfair ones provoking negativity (as is the default description). That is, while unfair and very unfair (3.18 and $3.22 \mu \mathrm{V}$ ) indeed evoked 
negativity versus fair $(4.33 \mu \mathrm{V})$ offers, so did generous offers $(3.22 \mu \mathrm{V})$. This exclusive, positive effect of fairness, relative to the negative effect of generous offers prompted the analysis referred to in 2.7 as the analysis of offer size - i.e. following up any analysis showing a significant effect of fairness with one that included all offer types but for the fair one. Here, the effect of offer size (very unfair, fair, vs generous offers) was found non-significant, $p=.95$, $\eta_{p}^{2}=.001$, power $=.02$, nor was the interaction between offer size and electrode, $\mathrm{p}=.92, \eta_{p}^{2}=.004$, power $=.03$. Put next to one another, the analyses of fairness and offer size thus reveal the effect of fairness is exclusively defined by fair offer specific activity.

\subsubsection{Effects of emotional expression and fairness on $\mathrm{P3}$}

Repeated measures ANOVAs on the average amplitude of the P3 interval with electrode, fairness and emotional expression showed significant effects of fairness, $\mathrm{F}(2.45,137.35)=5.69, \mathrm{MSE}=22.69, \mathrm{p}=$ $.002, \eta_{p}^{2}=.09$, and emotional expression, $\mathrm{F}(1.81$, $101.32)=16.49, \mathrm{MSE}=12.87, \mathrm{p}<.001, \eta_{p}^{2}=.23$. Fairness showed maximum negativity with unfair offers $(1.32 \mu \mathrm{V})$ followed by generous $(1.82 \mu \mathrm{V})$, very unfair $(2.21 \mu \mathrm{V})$ and fair $(2.32 \mu \mathrm{V})$ ones. Emotional expression showed similar effects to those on MFN, with neutral expressions $(1.31 \mu \mathrm{V})$ evoking a lower amplitude than angry $(2.13 \mu \mathrm{V})$ and happy $(2.31 \mu \mathrm{V})$ expressions. Moreover, fairness interacted with electrode, $F(3.42,191.45)=16.33$, MSE $=3.10, p<$ $.001, \eta_{p}^{2}=.23$. Fair offers now evoked positivity over the parietal (4.32 in fair vs $2.67 \mu \mathrm{V}$ in unfair conditions) and central ( $2.05 \mu \mathrm{V}$ vs $0.82 \mu \mathrm{V})$ sites, but not over the frontal (1.45 in very unfair vs $0.61 \mu \mathrm{V}$ in fair conditions) one. Emotional expression also interacted with fairness, $F(5.37,300.93)=3.62$, MSE $=6.63, p=.003, \eta_{p}^{2}=.06$. As shown in Figure 4 , the effect showed positivity to be strongest for angry/fair $(2.99 \mu \mathrm{V})$ and happy/very unfair $(2.61 \mu \mathrm{V})$ offers and weakest for neutral/unfair $(0.59 \mu \mathrm{V})$ conditions. To further illustrate this interaction between emotional expression and fairness, we calculated the fairness effect for each electrode as the difference between very unfair and fair conditions and show the scalp topography of this effect as a function of emotional expression. As can be seen in Figure 4, this shows that happy emotional expression amplified the frontal part of the P3, while attenuating the parietal part.

In contrast to the MFN analysis, substituting the fairness for the offer size factor did not change its significance, $\mathrm{F}(1.97,110.46)=7.74, \mathrm{MSE}=13.31, \mathrm{p}=$ $.001, \eta_{p}^{2}=.12$. However, offer size no longer interacted with emotional expression, $\mathrm{p}=.09$.

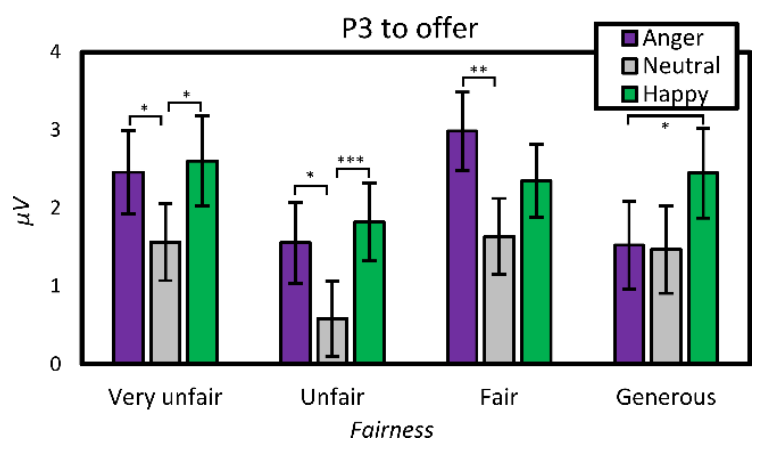

Figure 4: Effects of offer and emotional expression on $P 3$. P3 calculated as the area average over $\mathrm{Fz}, \mathrm{Cz}$, and $\mathrm{Pz}$ electrodes. Error bars show standard error of means.

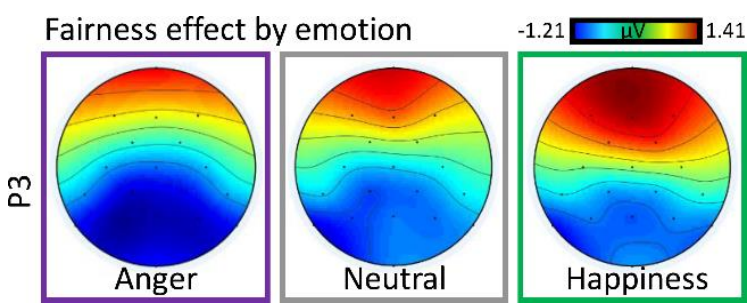

Figure 5: Emotional expression of the agent modulates fairness perception at the P3 window. The fairness effect was calculated as the difference between very unfair and fair conditions.

\subsubsection{Effects of emotional expression and fairness on LPP}

In a repeated measures ANOVA on the average amplitude in the LPP interval with fairness, electrode and emotional expression, both fairness, $\mathrm{F}$ (2.51, $140.59)=31.39, \mathrm{MSE}=24.39, \mathrm{p}<.001, \eta_{p}^{2}=.36$, and emotional expression, $\mathrm{F}(1.97,110.36)=16.58$, MSE $=12.39, \mathrm{p}<.001, \eta_{p}^{2}=.23$, were significant. Emotional expression showed a smaller LPP after neutral $(0.17 \mu \mathrm{V})$ than angry $(1.08 \mu \mathrm{V})$ and happy $(1.14 \mu \mathrm{V})$ expressions. Fairness showed a negativity for fair conditions $(-0.75 \mu \mathrm{V})$ as opposed to unfair $(0.83 \mu \mathrm{V})$, offer size $(1.22 \mu \mathrm{V})$ and very unfair (1.88 $\mu \mathrm{V})$ ones. Fairness also interacted with electrode, $\mathrm{F}$ $(3.40,190.65)=3.97, \mathrm{MSE}=3.59, \mathrm{p}=.006, \eta_{p}^{2}=.07$, showing the negativity associated with fairness as most prevalent over the frontal site $(-1.27 \mu \mathrm{V})$ whereas the positivity associated with the very unfair condition was most marked over the parietal site $(2.66 \mu \mathrm{V})$.

Substituting offer size for fairness did not remove the effect of offer size, $\mathrm{F}(1.97,110.10)=9.71$, MSE = $15.17, \mathrm{p}<.001, \eta_{p}^{2}=.15$, nor the interaction between offer size and electrode, $\mathrm{F}(2.55,142.75)=6.47$, MSE $=2.63, \mathrm{p}=.001, \eta_{p}^{2}=.10$. 


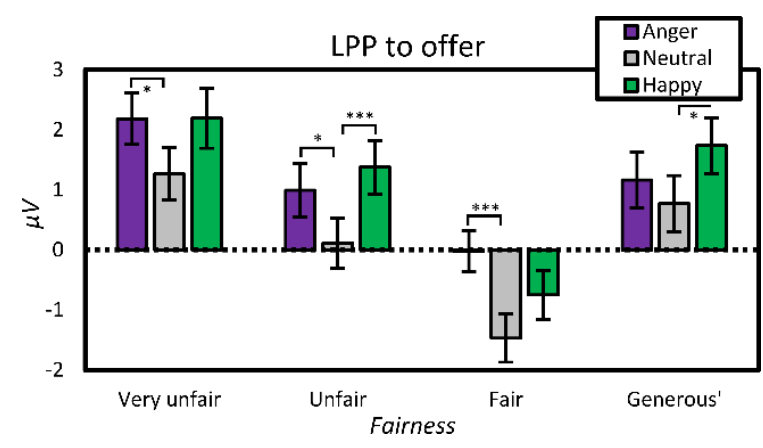

Figure 6: Effects of offer and emotional expression on LPP. LPP calculated as the area average over $\mathrm{Fz}, \mathrm{Cz}$, and $\mathrm{Pz}$ electrodes. Error bars show standard error of means.

\subsection{Effects of touch on offer perception}

A repeated measures ANOVA with time (N1, MFN, $\mathrm{P} 3, \mathrm{LPP})$, electrode (Fz, Cz, Pz), fairness, and touch showed a significant effect of touch, $F(1.88,105.46)$ $=4.21, \mathrm{MSE}=34.34, \mathrm{p}=.02, \eta_{p}^{2}=.07$. Visual touch conditions overall evoked higher amplitudes (0.92 $\mu \mathrm{V})$ than no touch $(0.49 \mu \mathrm{V})$ and tactile touch conditions $(0.58 \mu \mathrm{V})$. Touch furthermore interacted with electrode, $\mathrm{F}(3.05,170.66)=10.57, \mathrm{MSE}=3.80$, $\mathrm{p}<.001, \eta_{p}^{2}=.16$, generally showing stronger effects in frontal and central electrodes than parietal ones (see Figure 7). A significant interaction was also observed between touch and time, $\mathrm{F}(4.24,237.18)=$ 2.80, $\mathrm{MSE}=5.12, \mathrm{p}=.02, \eta_{p}^{2}=.05$, which in turn was modulated by electrode, $\mathrm{F}(5.03,281.71)=2.51$, MSE $=0.96, \mathrm{p}=.03, \eta_{p}^{2}=.04$.

To further inspect the effect of touch, we used separate 3-way ANOVAs for each of the four potentials. Note that we omit from the report all redundant effects that have already been reported under 3.2 (e.g. the main effect of fairness). Please see 3.2.1 for main effects and interactions between time, electrode, and fairness.

\subsubsection{Effects of touch on $\mathbf{N} 1$}

A repeated measures ANOVA on the average amplitude for $\mathrm{N} 1$ with electrode, fairness, and touch as factors, showed no significant main effect of touch, $\mathrm{p}=.39, \eta_{p}^{2}=.02$, power $=.09$. However, touch significantly interacted with electrode, F (2.79, $156.34)=8.45, \mathrm{MSE}=0.94, \mathrm{p}<.001, \eta_{p}^{2}=.13$. The strongest effect of touch was observed over the frontal site, with more negativity after tactile touch $(-4.74 \mu \mathrm{V})$ than after no $(-4.58 \mu \mathrm{V})$ or visual $(-4.32 \mu \mathrm{V})$ touch. Touch did not enter into any other interaction, $p s>.25$. As the $\mathrm{N} 1$ is generally more pronounced over frontal sites, this may indicate an enhanced N1 after tactile touch.

\subsubsection{Effects of touch on MFN}

A repeated measures ANOVA on the MFN showed similar effects, with touch significantly interacting with electrode, $\mathrm{F}(2.99,167.34)=10.83, \mathrm{MSE}=1.17$, $\mathrm{p}<.001, \eta_{p}^{2}=.16$, but not as a main effect, $\mathrm{p}=.04$, $\eta_{p}^{2}=.06$, power $=.40$. However, here no touch and tactile touch showed negativity $(1.72,1.79 \mu \mathrm{V})$ relative to visual touch $(2.31 \mu \mathrm{V})$ over the frontal electrode, as well as over the central site $(2.01,2.24$ vs $2.62 \mu \mathrm{V}$ ). As shown in figure 4 , few effects of touch were obtained over the parietal site. Touch did not interact with any other factor, $p s>.12$.

\subsubsection{Effects of touch on P3}

Similar ANOVAs on the P3 showed a significant main effect of touch, $\mathrm{F}(1.86,103.92)=5.66, \mathrm{MSE}=14.34$, $\mathrm{p}=.006, \eta_{p}^{2}=.09$, as well as an interaction between touch and electrode, $\mathrm{F}(2.99,167.16)=8.76, \mathrm{p}<.001$, $\eta_{p}^{2}=.14$. In general, visual touch evoked an amplified $\mathrm{P} 3(2.28 \mu \mathrm{V})$ relative to tactile $(1.82 \mu \mathrm{V})$ or no $(1.64$ $\mu \mathrm{V})$ touch conditions. This effect was stronger in central (1.95 vs 1.44 and $0.96 \mu \mathrm{V}$ ) and frontal (1.33 vs 0.67 and $0.60 \mu \mathrm{V}$ ) sites and virtually absent over the parietal site. Touch did not interact with any other factor, $p s>.19$.

\subsubsection{Effects of touch on LPP}

A final repeated measures ANOVA on the LPP showed no significant main effect of touch, $p=.03$. Similar to the previous analyses, however, touch did interact with electrode, $\mathrm{F}(3.04,170.09)=5.93$, MSE $=1.84, \mathrm{p}=.001, \eta_{p}^{2}=.10$. A pattern that was very similar to the P3 effects was observed: visual touch evoked slightly more activity over frontal LPPs (0.66 $\mu \mathrm{V})$ and central $(1.16 \mu \mathrm{V})$ sites than no touch $(0.10$, $0.30 \mu \mathrm{V})$ and tactile touch $(0.10,0.81 \mu \mathrm{V})$. Touch did not interact with any other factor, $p s>.53$.
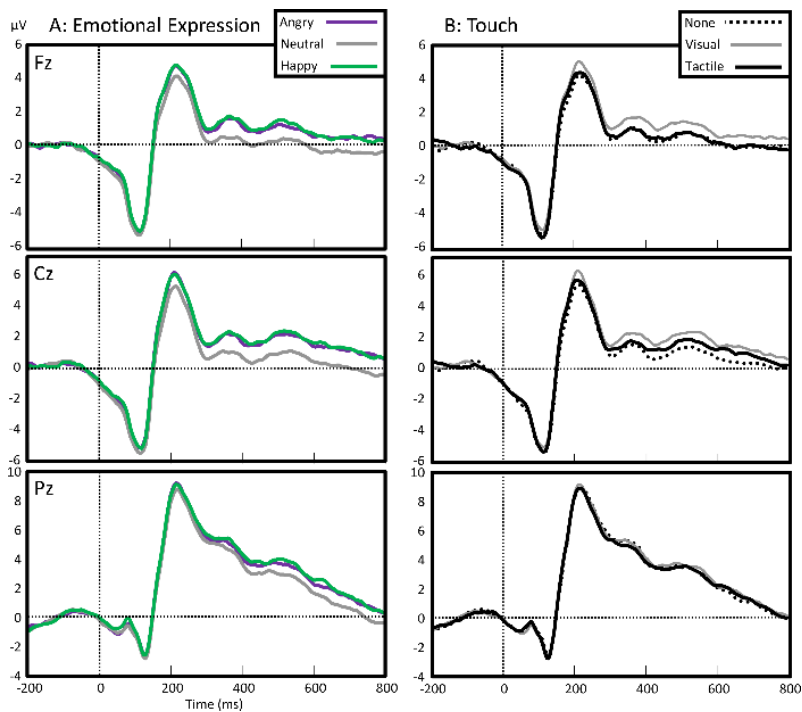

Figure 7: Event related potential to offers as a function of non-verbal communication. Potentials are related to the emotional expression (left) and type of touch (right) displayed by the agent (left), but time-locked to and averaged across the four types of offers. 


\section{Discussion}

The aim of the present study was to investigate whether and when a messenger's non-verbal behaviour influences our perception of what a message signifies. To this end, we presented artificial agents in virtual reality who displayed two distinct non-verbal communication channels, emotional expressions and interpersonal touch, prior to making economic proposals. In line with previous behavioural Ultimatum Game studies (Mussel et al., 2013), participants were found to reject unfair offers more than fair ones, and that angry expressions increased this difference. Interpersonal touch was not found to promote compliance, contrary to studies reporting a Midas Touch-Effect (Gueguen \& De Gail, 2003).

\subsection{Fairness perception and the MFN}

The ERP analysis showed unfair offers evoked medial frontal negativity (MFN) relative to fair offers, which has previously been related to perception of a social norm of fairness being violated (Boksem \& De Cremer, 2010). The present study provides evidence against a social-emotional interpretation of the MFN on two accounts. First, we show that although emotional expressions did affect the behavioural consequence to unfairness, they had no modulatory effect on the MFN. Second, we unexpectedly observed pronounced MFN to generous offers as much as unfair ones. In our discussion, we will first devote some attention to the implication of our results for fairness perception. We then discuss the degree to which non-verbal communication affects offer perception, as measured using other components of the ERP. Finally, we give an account of how the findings favour a late message-messenger integration account of neurosemiotics.

There are at least two explanations for the dissociations between behavioural responses and neural correlates, although neither fits well with the fairness norm violation account. A first possibility is that there are two stages of unfairness perception: a primary error response, and a secondary attribution response. In this error-attribution model, a first process examines whether an economic offer is unfair or not without consideration for the target of the treatment - a generous offer is therefore still unfair. Only at a later stage do we disentangle whether this matters to ourselves, or whether it affects our interaction partner. This explanation is supported by the findings of De Bruijn and Von Rhein (2012), who showed that another's mistakes provoke ERNs in the observer even if such mistakes hold positive significance for the observer (i.e. if the other's mistake is made in a competitive context). A second, stronger explanation is that the MFN does not concern a detection of negative, erroneous outcomes, but rather qualifies a stimulus as not matching a receiver's expectations regarding the message. Support for this expectancy-deviation account comes from studies examining the function of FRN in performance monitoring paradigms. These studies show that both unexpectedly positive and negative feedback regarding one's performance amplify the FRN (e.g., Oliveira et al., 2007). Likewise, the FRN has also been observed in a shopping scenario in which valuable items were shown to unexpectedly low prices (Schaefer, Buratto, Goto, \& Brotherhood, 2016). In other words, the more parsimonious explanation suggests that the MFN in the Ultimatum Game is a correlate to a general, 'cold' classification of proposals as equal or not equal to a predicted stimulus.

\subsection{Non-verbal communication and offer perception}

While neither non-verbal modality affected the MFN, we did observe emotional expressions to modulate later components related to offer perception. Following the MFN, during which unfairness itself was processed, yet the type of unfairness was not, more fine-grained emotional appraisal of the offer took place after ca. $400 \mathrm{~ms}$. Thus, at the stage of the P3, which has previously been shown to dissociate the probabilities of outcomes (Hajcak, Holroyd, Moser, \& Simons, 2005) and prediction errors in decision-making tasks (e.g., Bellebaum \& Daum, 2008), very unfair offers were dissociated from other proposals. Subsequently, at the time of the LPP, all four types of offers were finally dissociated, although at no point did they 'economically' align: very unfair and generous offers had an amplified LPP effect relative to the unfair and fair ones. This is theoretically interesting from the point of view that various studies used the LPP as a simple index of motivation (Bamford et al., 2015; Gable \& Harmon-Jones, 2010). However, accounts suggesting a more evaluative role of the LPP (e.g. Schupp, Flaisch, Stockburger, \& Junghöfer, 2006) were supported in our study, as both positive (generous) and negative (very unfair) conditions had relatively amplified LPPs.

The other non-verbal modality, touch, did not play a systematic role in offer processing or decisionmaking behaviour. Interpersonal touch does not, however, reliably affect decision-making. In our earlier studies, we found the physiological influences of symbolic touch to proposer feedback in the Ultimatum Game to occur later than expected (Spapé et al., 2015), while others found that even Ctactile optimized touch does not necessarily increase prosocial behaviour (Rosenberger, Ree, Eisenegger, \& Sailer, 2018). Recently, we found the persuasive effect of touch to be strongly dependent on various 
situational and personality level factors (Harjunen, Spapé, Ahmed, Jacucci, \& Ravaja, 2018). It seems therefore likely that the Midas Touch-Effect does not rely on an unconscious, automatic tendency to evaluate stimuli as more positive, but is instead based on a complex appraisal process, which takes circumstances of the message and the messenger into account.

\subsection{Of the message and the messenger}

The temporal dynamics of offer perception holds critical clues in the understanding of how the wider meaning of a message, in the context provided by the messenger, is decoded. Emotional expressions do not seem to modulate fairness perception in earlier (N1/MFN) processing stages. It therefore seems likely that the nature of the offer is decoded before the emotional expression is taken into account. As social expectations are critical for our development (Nummenmaa \& Calder, 2009; Todd, Lewis, Meusel, \& Zelazo, 2008), one might expect them to affect us very early in terms of cognitive processing, such that an emotional expression causes top-down changes in expectations: a happy expression should naturally lead to a social norm of fairness or generosity. While changes in offer perception were indeed observed, they did not yet occur within the time range of the MFN (but see Ma et al., 2017). Therefore, the present study suggests that contextual influences, such as facial emotional cues, manifest only at a relatively late stage, before which the offer is processed relatively independently of its context.

In conclusion, at an early stage of processing, fairness perception is paradoxically not very subjective. Of course, fairness is not an objective quality: Without a subject finding a message to not match their expectation, there would be no fairness. The study shows, however, that despite non-verbal communications changing how we respond to subsequent messages, our earliest fairness perception to these messages remains unaffected. Indeed, at this stage, evaluation appears a cold, rational process: We do not yet determine who the target of the unfairness is, do not dissociate unfairness from generosity. Only after a message is decoded as dichotomously equal or unequal does the degree of subjective fairness become apparent, and only then does the non-verbal context become involved. Accordingly, non-verbal communication does not seem to immediately, inevitably affect the semiotics of the message and the messenger. In other words, we understand the meaning of 'who says what' in precisely the other order: of the message, then the messenger.

\section{Acknowledgements}

This work was supported by the Academy of Finland, grant 268999.

\section{Open practices statement}

The experiment was not preregistered. Data and materials for the experiment reported here are available from OSF (DOI 10.17605/OSF.IO/6EA8S), including epoched EEG data and MATLAB analysis code.

\section{References}

Ahmed, I., Harjunen, V., Jacucci, G., Hoggan, E., Ravaja, N., \& Spapé, M. M. (2016). Reach out and touch me: effects of four distinct haptic technologies on affective touch in virtual reality. Proceedings of the 18th ACM International Conference on Multimodal Interaction, 341-348.

Bamford, S., Broyd, S. J., Benikos, N., Ward, R., Wiersema, J. R., \& Sonuga-Barke, E. (2015). The late positive potential: A neural marker of the regulation of emotion-based approach-avoidance actions? Biological Psychology, 105, 115-123.

Barrett, L. F., Lindquist, K. A., \& Gendron, M. (2007). Language as context for the perception of emotion. Trends in Cognitive Sciences, 11(8), 327-332.

Boksem, M. A., \& De Cremer, D. (2010). Fairness concerns predict medial frontal negativity amplitude in ultimatum bargaining. Social Neuroscience, 5(1), 118-128.

Chatrian, G. E., Lettich, E., \& Nelson, P. L. (1985). Ten percent electrode system for topographic studies of spontaneous and evoked EEG activities. American Journal of EEG Technology, 25(2), 83-92.

Crusco, A. H., \& Wetzel, C. G. (1984). The Midas touch The effects of interpersonal touch on restaurant tipping. Personality and Social Psychology Bulletin, 10(4), 512-517.

de Melo, C., Gratch, J., Carnevale, P., \& Read, S. (2012). Reverse appraisal: The importance of appraisals for the effect of emotion displays on people's decision making in a social dilemma. Proceedings of the Annual Meeting of the Cognitive Science Society, 34.

Delorme, A., \& Makeig, S. (2004). EEGLAB: an open source toolbox for analysis of single-trial EEG dynamics including independent component analysis. Journal of Neuroscience Methods, 134(1), 9-21.

Detenber, B. H., Simons, R. F., \& Reiss, J. E. (2000). The emotional significance of color in television presentations. Media Psychology, 2(4), 331-355.

Donchin, E., \& Coles, M. G. (1988). Is the P300 component a manifestation of context updating? Behavioral and Brain Sciences, 11(03), 357-374.

Ekman, P., \& Friesen, W. V. (1971). Constants across cultures in the face and emotion. Journal of Personality and Social Psychology, 17(2), 124. 
Eviatar, Z., \& Just, M. A. (2006). Brain correlates of discourse processing: An fMRI investigation of irony and conventional metaphor comprehension. Neuropsychologia , 44(12), 2348-2359.

Fisher, J. D., Rytting, M., \& Heslin, R. (1976). Hands touching hands: Affective and evaluative effects of an interpersonal touch. Sociometry, 416-421.

Folstein, J. R., \& Van Petten, C. (2008). Influence of cognitive control and mismatch on the N2 component of the ERP: a review. Psychophysiology, 45(1), 152-170.

Friedman, D., Cycowicz, Y. M., \& Gaeta, H. (2001). The novelty P3: an event-related brain potential (ERP) sign of the brain's evaluation of novelty. Neuroscience \& Biobehavioral Reviews, 25(4), 355373.

Gable, P. A., \& Harmon-Jones, E. (2010). Late positive potential to appetitive stimuli and local attentional bias. Emotion, 10(3), 441.

Gallace, A., \& Spence, C. (2010). The science of interpersonal touch: an overview. Neuroscience \& Biobehavioral Reviews, 34(2), 246-259.

Gazzola, V., Spezio, M. L., Etzel, J. A., Castelli, F., Adolphs, R., \& Keysers, C. (2012). Primary somatosensory cortex discriminates affective significance in social touch. Proceedings of the National Academy of Sciences, 109(25), 16571666.

Gehring, W. J., Goss, B., Coles, M. G., Meyer, D. E., \& Donchin, E. (1993). A neural system for error detection and compensation. Psychological Science, 4(6), 385-390.

Gehring, W. J., \& Willoughby, A. R. (2002). The medial frontal cortex and the rapid processing of monetary gains and losses. Science, 295(5563), 2279-2282.

Gehring, W. J., \& Willoughby, A. R. (2004). Are all medial frontal negativities created equal? Toward a richer empirical basis for theories of action monitoring. Errors, Conflicts, and the Brain. Current Opinions on Performance Monitoring, 14-20.

Goldman, M., \& Fordyce, J. (1983). Prosocial behavior as affected by eye contact, touch, and voice expression. The Journal of Social Psychology, 121(1), 125-129.

Gueguen, N., \& De Gail, M.-A. (2003). The effect of smiling on helping behavior: Smiling and good Samaritan behavior. Communication Reports, 16(2), 133-140.

Guéguen, N., \& Fischer-Lokou, J. (2003). Another evaluation of touch and helping behavior. Psychological Reports, 92(1), 62-64.

Güth, W., Schmittberger, R., \& Schwarze, B. (1982). An experimental analysis of ultimatum bargaining. Journal of Economic Behavior \& Organization, 3(4), 367-388.
Hajcak, G., Holroyd, C. B., Moser, J. S., \& Simons, R. F. (2005). Brain potentials associated with expected and unexpected good and bad outcomes. Psychophysiology, 42(2), 161-170.

Harjunen, V., Spapé, M., Ahmed, I., Jacucci, G., \& Ravaja, N. (2018). Persuaded by the machine: The effect of virtual nonverbal cues and individual differences on compliance in economic bargaining. Computers in Human Behavior, 87, 384-394.

Harjunen, Ville J., Ahmed, I., Jacucci, G., Ravaja, N., \& Spapé, M. M. (2017). Manipulating bodily presence affects cross-modal spatial attention: A virtualreality-based ERP study. Frontiers in Human Neuroscience, 11.

Harter, M. R., \& Previc, F. H. (1978). Size-specific information channels and selective attention: Visual evoked potential and behavioral measures. Electroencephalography and Clinical Neurophysiology, 45(5), 628-640.

Hinojosa, J. A., Mercado, F., \& Carretié, L. (2015). N170 sensitivity to facial expression: A metaanalysis. Neuroscience \& Biobehavioral Reviews, 55, 498-509.

Holmes, A., Vuilleumier, P., \& Eimer, M. (2003). The processing of emotional facial expression is gated by spatial attention: evidence from event-related brain potentials. Cognitive Brain Research, 16(2), 174-184.

Holroyd, C. B., \& Coles, M. G. (2002). The neural basis of human error processing: reinforcement learning, dopamine, and the error-related negativity. Psychological Review, 109(4), 679.

Kahneman, D., Treisman, A., \& Gibbs, B. J. (1992). The reviewing of object files: Object-specific integration of information. Cognitive Psychology, 24(2), 175-219.

Krolak-Salmon, P., Fischer, C., Vighetto, A., \& Mauguière, F. (2001). Processing of facial emotional expression: spatio-temporal data as assessed by scalp event-related potentials. European Journal of Neuroscience, 13(5), 987-994. Luo, W., Feng, W., He, W., Wang, N.-Y., \& Luo, Y.-J. (2010). Three stages of facial expression processing: ERP study with rapid serial visual presentation. Neurolmage, 49(2), 1857-1867.

Mehrabian, A., \& Ferris, S. R. (1967). Inference of attitudes from nonverbal communication in two channels. Journal of Consulting Psychology, 31(3), 248.

Mehrabian, A., \& Wiener, M. (1967). Decoding of inconsistent communications. Journal of Personality and Social Psychology, 6(1), 109.

Moser, A., Gaertig, C., \& Ruz, M. (2014). Social information and personal interests modulate neural activity during economic decision-making. Frontiers in Human Neuroscience, 8, 31. 
Mussel, P., Göritz, A. S., \& Hewig, J. (2013). The value of a smile: Facial expression affects ultimatumgame responses. Judgment and Decision Making, 8(3), 381.

Nieuwenhuis, S., Yeung, N., van den Wildenberg, W., \& Ridderinkhof, K. R. (2003). Electrophysiological correlates of anterior cingulate function in a go/nogo task: effects of response conflict and trial type frequency. Cognitive, Affective \& Behavioral Neuroscience, 3(1), 17-26.

Nummenmaa, L., \& Calder, A. J. (2009). Neural mechanisms of social attention. Trends in Cognitive Sciences, 13(3), 135-143.

Polezzi, D., Daum, I., Rubaltelli, E., Lotto, L., Civai, C., Sartori, G., \& Rumiati, R. (2008). Mentalizing in economic decision-making. Behavioural Brain Research, 190(2), 218-223.

Ravaja, N. (2004). Effects of image motion on a small screen on emotion, attention, and memory: Moving-face versus static-face newscaster. Journal of Broadcasting \& Electronic Media, 48(1), 108133.

Ravaja, N., Harjunen, V., Ahmed, I., Jacucci, G., \& Spapé, M. M. (2017). Feeling touched: Emotional modulation of somatosensory potentials to interpersonal touch. Scientific Reports, 7, 40504.

Reeves, B., Lang, A., Kim, E. Y., \& Tatar, D. (1999). The effects of screen size and message content on attention and arousal. Media Psychology, 1(1), 4967.

Rosenberger, L. A., Ree, A., Eisenegger, C., \& Sailer, U. (2018). Slow touch targeting CT-fibres does not increase prosocial behaviour in economic laboratory tasks. Scientific Reports, 8(1), 7700.

Sanfey, A. G., Rilling, J. K., Aronson, J. A., Nystrom, L. E., \& Cohen, J. D. (2003). The neural basis of economic decision-making in the ultimatum game. Science, 300(5626), 1755-1758.

Schirmer, A., Teh, K. S., Wang, S., Vijayakumar, R., Ching, A., Nithianantham, D., ... Cheok, A. D. (2010). Squeeze me, but don't tease me: Human and mechanical touch enhance visual attention and emotion discrimination. Social Neuroscience, 6(3), 219-230.

Schupp, H. T., Flaisch, T., Stockburger, J., \& Junghöfer, M. (2006). Emotion and attention: event-related brain potential studies. Progress in Brain Research, 156, 31-51.

Schupp, H. T., Junghöfer, M., Weike, A. I., \& Hamm, A. O. (2003). Attention and emotion: an ERP analysis of facilitated emotional stimulus processing. Neuroreport, 14(8), 1107-1110.

Schupp, H. T., Öhman, A., Junghöfer, M., Weike, A. I., Stockburger, J., \& Hamm, A. O. (2004). The facilitated processing of threatening faces: an ERP analysis. Emotion, 4(2), 189.
Schupp, H. T., Schmälzle, R., Flaisch, T., Weike, A. I., \& Hamm, A. O. (2013). Reprint of "Affective picture processing as a function of preceding picture valence: an ERP analysis." Biological Psychology, 92(3), 520-525.

Spapé, M. M., Harjunen, V. J., \& Ravaja, N. (2017). Effects of touch on emotional face processing: A study of event-related potentials, facial EMG and cardiac activity. Biological Psychology.

Spapé, M. M., Hoggan, E. E., Jacucci, G., \& Ravaja, N. (2015). The meaning of the virtual Midas touch: An ERP study in economic decision making. Psychophysiology, 52(3), 378-398.

Spitz, M. C., Emerson, R. G., \& Pedley, T. A. (1986). Dissociation of frontal N100 from occipital P100 in pattern reversal visual evoked potentials. Electroencephalography and Clinical Neurophysiology/Evoked Potentials Section, 65(3), 161-168.

Squires, N. K., Squires, K. C., \& Hillyard, S. A. (1975). Two varieties of long-latency positive waves evoked by unpredictable auditory stimuli in man. Electroencephalography and Clinical Neurophysiology, 38(4), 387-401.

Sutton, S., Braren, M., Zubin, J., \& John, E. R. (1965). Evoked-potential correlates of stimulus uncertainty. Science, 150(3700), 1187-1188.

Sutton, S., Tueting, P., Zubin, J., \& John, E. R. (1967). Information delivery and the sensory evoked potential. Science, 155(3768), 1436-1439.

Ting-Toomey, S. (1999). Communicating across cultures. New York, NY: Guilford Press.

Todd, R. M., Lewis, M. D., Meusel, L.-A., \& Zelazo, P. D. (2008). The time course of social-emotional processing in early childhood: ERP responses to facial affect and personal familiarity in a Go-Nogo task. Neuropsychologia, 46(2), 595-613.

Treisman, A. (1996). The binding problem. Current Opinion in Neurobiology, 6(2), 171-178.

Van der Veen, F. M., \& Sahibdin, P. P. (2011). Dissociation between medial frontal negativity and cardiac responses in the ultimatum game: effects of offer size and fairness. Cognitive, Affective, \& Behavioral Neuroscience, 11(4), 516-525.

von Neumann, J., \& Morgenstern, O. (1944). Theory of games and economic behavior. New Jersey, NJ: Princeton University Press.

Vrugt, A. (2007). Effects of a smile: Reciprocation and compliance with a request. Psychological Reports, 101, 1196-1202.

Wu, Y., Zhou, Y., van Dijk, E., Leliveld, M. C., \& Zhou, $X$. (2011). Social comparison affects brain responses to fairness in asset division: an ERP study with the ultimatum game. Frontiers in Human Neuroscience, 5.

Yeung, N., Botvinick, M. M., \& Cohen, J. D. (2004). The neural basis of error detection: conflict 
monitoring and the error-related negativity. Psychological Review, 111(4), 931.
Zhang, D., Luo, W., \& Luo, Y. (2013). Single-trial ERP analysis reveals facial expression category in a three-stage scheme. Brain Research, 1512, 78-88.

\section{Supplemental material}

\subsection{Supplemental material 1: Outcome of full factorial analysis}

A repeated measures ANOVA on the average amplitude with time (N1, MFN, P3, LPP), electrode (Fz, Cz, Pz), emotional expression (angry, neutral, happy), touch (no touch, visual touch, visuo-tactile touch), and fairness (very unfair, unfair, fair, generous) showed significant main effects of time, $\mathrm{F}(2.42,135.46)=103.31$, MSE = 541.64, $\mathrm{p}<.001, \eta_{p}^{2}=.65$, emotional expression, $\mathrm{F}(2,112)=14.16, \mathrm{p}<.001, \mathrm{MSE}=93.09, \eta_{p}^{2}=.20$, touch, $\mathrm{F}(2$, $112)=4.39, \mathrm{p}=.01, \eta_{p}^{2}=.07$, but not offer size, $\mathrm{p}=.09$. Significant interactions were observed between time and electrode, $\mathrm{F}(6,336)=28.24, \mathrm{p}<.001, \mathrm{MSE}=50.91, \eta_{p}^{2}=.34$; between time and offer size, $\mathrm{F}(5.19,290.73)=$ $33.94, \mathrm{p}<.001, \mathrm{MSE}=24.85, \eta_{p}^{2}=.38$; between electrode and offer size, $\mathrm{F}(3.93,219.88)=4.17, \mathrm{p}=.003, \mathrm{MSE}=$ $9.11, \eta_{p}^{2}=.07$. These identified, successively, temporal and topographical differences between ERPs, and an effect of offer size that was qualified by time and electrode (see figure 2). Electrode, time, and offer size also entered into a significant three-way interaction, $\mathrm{F}(6.28,351.39)=11.07, \mathrm{p}<.001, \mathrm{MSE}=2.42, \eta_{p}^{2}=.16$. With regards to emotional expression and touch, significant interactions were observed between time and emotional expression, $\mathrm{F}(4.69,262.46)=6.12, \mathrm{p}<.001, \mathrm{MSE}=10.04, \eta_{p}^{2}=.10$, and between electrode and emotional expression, $\mathrm{F}(2.78,155.79)=3.62, \mathrm{p}=.02$, MSE $=7.61, \eta_{p}^{2}=.06$. These effects are described in more detail in section 3.2 and figure $4 \mathrm{~A}$. Significant interactions were also observed between time and touch, $F(4.24,237.37)$ $=2.93, \mathrm{p}=.02, \mathrm{MSE}=11.32, \eta_{p}^{2}=.05$; between electrode and touch, $\mathrm{F}(3.06,171.24)=10.60, \mathrm{p}<.001, \mathrm{MSE}=$ $8.71, \eta_{p}^{2}=.16$; and in the three-way interaction between time, electrode, and touch, $\mathrm{F}(4.95,277.14)=2.50, \mathrm{p}=$ $.03, \mathrm{MSE}=1.24, \eta_{p}^{2}=.04$.

Of particular interest to the present study were interactions between the non-verbal interaction channels emotional expression and touch - on the one hand and offer size on the other. This was observed for emotional expression, with a significant 3-way interaction between time, emotional expression, and offer size, F (10.80, $604.58)=2.74, \mathrm{p}=.002, \mathrm{MSE}=8.19, \eta_{p}^{2}=.05$. Touch, however, did not enter in any further interaction with offer size, $p s>.38$, or emotion, $p s>.18$, or both, $p s>.17$. In section 3.2 , we further investigated the effects of emotional expression by averaging epochs across touch conditions, maximising power and precision for detecting the particular interval at which this interaction occurs (section 3.2). For completeness, we also include the same analysis for the effect of touch (averaging epochs across emotion condition). 
Table 1

Full factorial model results

\begin{tabular}{|c|c|c|c|}
\hline Description & Factor & $F$ & $p$ \\
\hline Main effects & $\begin{array}{l}\text { Time } \\
\text { Electrode } \\
\text { Offer size } \\
\text { Emotional expression } \\
\text { Touch } \\
T * E\end{array}$ & $\begin{array}{r}103.31 \\
92.81 \\
2.21 \\
14.16 \\
4.39 \\
28.24\end{array}$ & 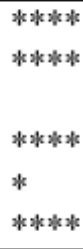 \\
\hline $\begin{array}{l}\text { Effects of fairness on the } \\
\text { ERP } x \text { time and electrode }\end{array}$ & $\begin{array}{l}T * \text { Offer } \\
E * \text { Offer } \\
T * E * \text { Offer }\end{array}$ & $\begin{array}{r}33.94 \\
4.17 \\
11.07 \\
\end{array}$ & $\begin{array}{l}\text { ***** } \\
* * * * \\
* * * * *\end{array}$ \\
\hline $\begin{array}{l}\text { Effects of emotion on the } \\
\text { ERP }\end{array}$ & $\begin{array}{l}T * E m o \\
E * E m o \\
T * E * E m o\end{array}$ & $\begin{array}{l}6.11 \\
3.62 \\
1.75 \\
\end{array}$ & $\begin{array}{l}\text { ***** } \\
*\end{array}$ \\
\hline $\begin{array}{l}\text { Effects of emotion on } \\
\text { fairness perception }\end{array}$ & $\begin{array}{l}\text { Offer * Emo } \\
T * \text { Offer * Emo } \\
E * \text { Offer * Emo } \\
T * E * \text { Offer * Emo }\end{array}$ & $\begin{array}{l}2.05 \\
2.74 \\
1.39 \\
0.93 \\
\end{array}$ & 水水 \\
\hline $\begin{array}{l}\text { Effects of touch on the } \\
\text { ERP }\end{array}$ & $\begin{array}{l}T * \text { Touch } \\
E * \text { Touch } \\
T * E * \text { Touch }\end{array}$ & $\begin{array}{r}2.93 \\
10.60 \\
2.50\end{array}$ & $\begin{array}{l}\text { * } \\
* * 2 * * * \\
*\end{array}$ \\
\hline $\begin{array}{l}\text { Effects of touch on } \\
\text { fairness perception }\end{array}$ & $\begin{array}{l}\text { Offer * Touch } \\
T * \text { Offer * Touch } \\
E^{*} \text { Offer * Touch } \\
T * E^{*} \text { Offer } * \text { Touch }\end{array}$ & $\begin{array}{l}0.90 \\
1.07 \\
0.93 \\
0.99\end{array}$ & \\
\hline Other interactions & 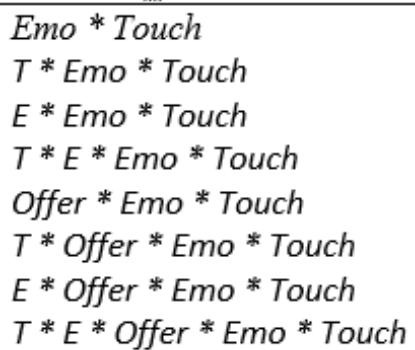 & $\begin{array}{l}0.82 \\
0.74 \\
1.54 \\
1.38 \\
0.93 \\
0.97 \\
0.36 \\
0.76\end{array}$ & \\
\hline
\end{tabular}

Note. Results of the full-factorial, five-way repeated measures ANOVA. Explanations of abbreviations of factors are underlined. The notes provide brief explanations of the tests within the present framework. Their significance was tested with GreenhouseGeisser adjustments where appropriate, with ${ }^{*}: p<.05 ;{ }^{* *}: p<.01 ;{ }^{* * *}: p<.005$, $* * * *$ : $p<.001$. 
8.2 Supplemental material 2: Emotional expressions and fairness, a complete analysis.

The presented figure shows the outcome of separate repeated measures ANOVAs with fairness (very unfair, unfair, fair, generous) and emotional expression (anger, neutral, happy) as factors. These were run on a total of 679 measures, all amplitude averages over $10 \mathrm{~ms}$ bins, from 180 before to $780 \mathrm{~ms}$, for 7 electrodes (Fz, FC1,

$\mathrm{FC} 2, \mathrm{Cz}, \mathrm{CP} 1, \mathrm{CP} 2$, and $\mathrm{Pz}$ ). Colours on top of each graph in the middle column indicate significance of the main effect of emotional expression (in black), of the main effect of fairness (in red), and of the interaction between fairness and emotional expression (in blue), the shade indicating the level of significance, with a threshold at $p$ $<.025$. Note that these tests are deliberately not corrected for multiple comparisons so as to indicate the most liberal interpretation of the data. In other words, the presented graphs may show many false positives - the reliability of very early effects is therefore very low. However, note that the first point at which the interaction between fairness and emotional expression reaches significance, is relatively late, even with these liberal criteria. The presented evidence thus shows 1) that emotional modulations of the fairness effect occurs after the fairness effect itself, and 2) that such modulations seem to principally occur over frontal sites.

Supplementary Material
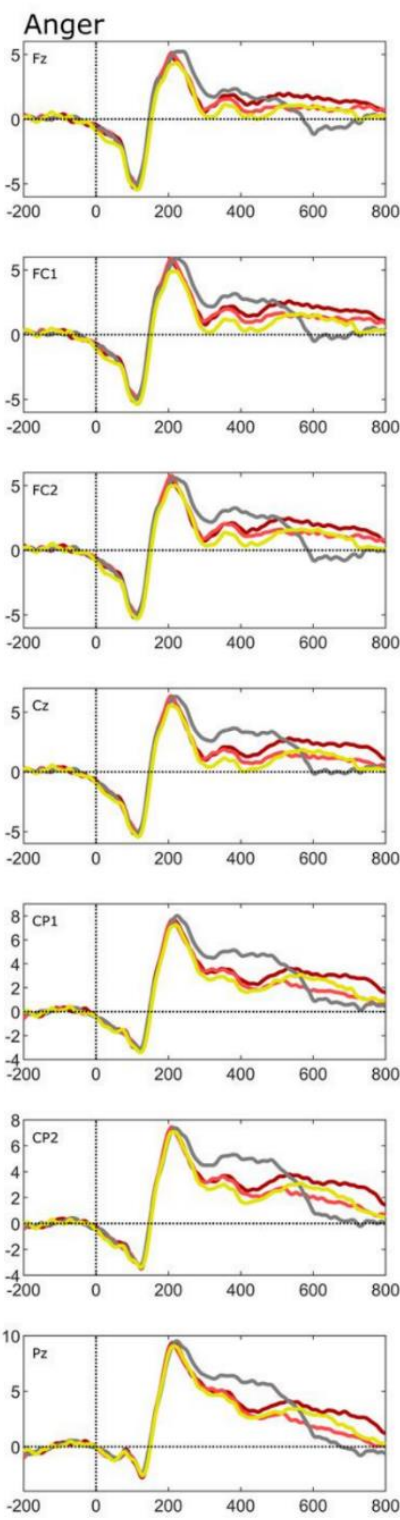
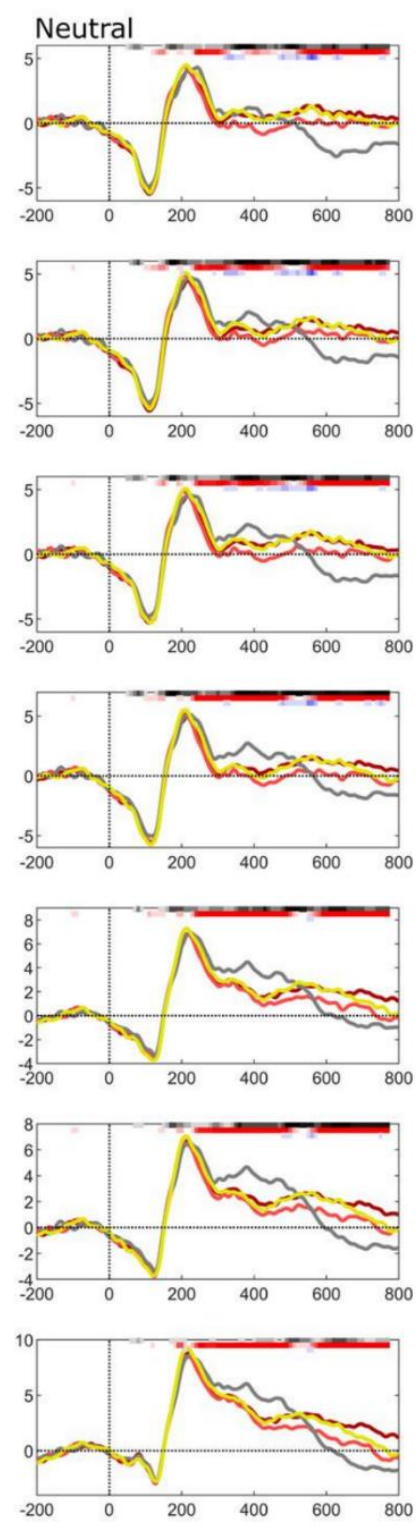
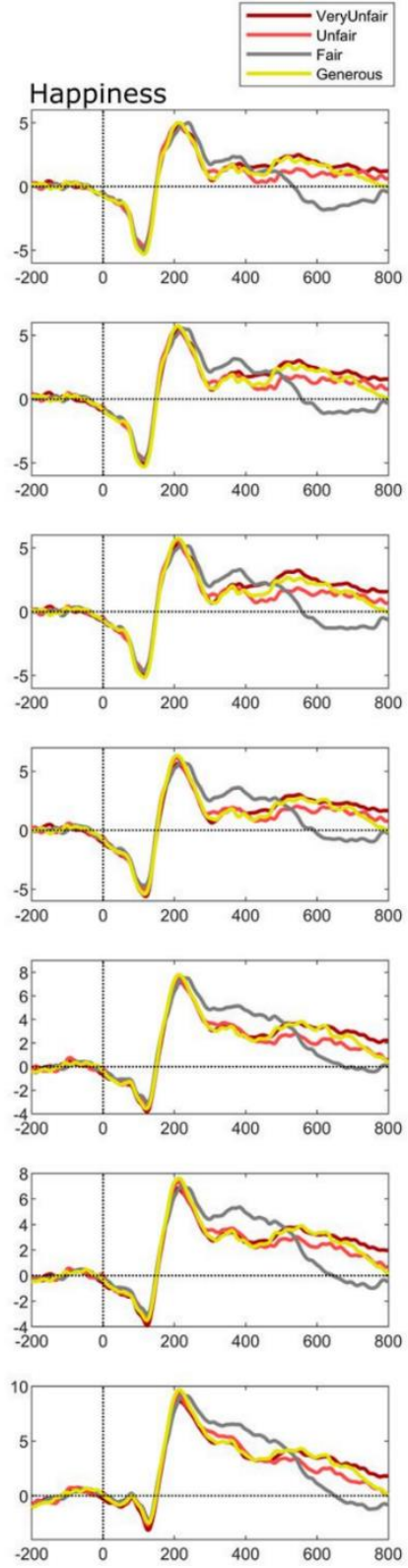

Figure 8: Effects of emotional expression and fairness on event related potentials. Coloured dots above the middle column indicate intervals in which tests yielded significant outcomes. A threshold of $p<.025$ was used, and the darkness of each dot indicates the significance of the test. Grey and black show the main effect of emotional expression, and red hues show the main effect of fairness. The interaction is shown in blue. 